Article

\title{
A Field Study on the Prevalence of and Risk Factors for Endoparasites in Beef Suckler Cow Herds in Germany
}

\author{
Kathia Gillandt ${ }^{1}$, Jenny Stracke ${ }^{1}$, Tatiana Hohnholz ${ }^{2}$, Ralf Waßmuth ${ }^{2}$ and Nicole Kemper ${ }^{1, *(D)}$ \\ 1 Institute for Animal Hygiene, Animal Welfare and Farm Animal Behaviour (ITTN), University of Veterinary \\ Medicine Hannover, Foundation, Bischhofsholer Damm 15 (Building 116), D-30173 Hannover, Germany; \\ kathia.gillandt@tiho-hannover.de (K.G.); jenny.stracke@tiho-hannover.de (J.S.) \\ 2 Faculty of Agricultural Sciences and Landscape Architecture, University of Applied Sciences Osnabrueck, \\ Am Kruempel 31, D-49090 Osnabrueck, Germany; t.hohnholz@hs-osnabrueck.de (T.H.); \\ R.Wassmuth@hs-osnabrueck.de (R.W.) \\ * Correspondence: nicole.kemper@tiho-hannover.de; Tel.: +49-511-856-8951
}

Received: 7 August 2018; Accepted: 25 August 2018; Published: 28 August 2018

\begin{abstract}
Endoparasites are one of the major health issues in beef suckler cows and can cause economic losses. As studies on the parasitological status of beef suckler cow herds are rare, the aim of this study was to evaluate the status quo of the parasite burden in herds at four representative locations in Germany. Additionally, the farmers' pasture management and deworming strategies were documented. Based on these data, the second aim of the study was to develop recommendations for improved deworming and pasture hygiene management. A total of 708 faecal samples were examined with parasitological routine methods. Results revealed Fasciola hepatica, gastrointestinal nematodes (GIN), Eimeria species (spp.), Moniezia spp. and Dictyocaulus viviparus as the most frequent findings. Clinical signs of parasitic diseases were not found during the farm visits. Statistical analyses showed a significant effect of the age status of the animal on the parasitological status in general. Due to the percentage of occurrence, detailed statistical analysis was performed for Eimeria, GIN and Fasciola hepatica, confirming the effect of age status. Assessing the parasitological status of beef suckler cows as routine procedure could help to establish an improved parasite-control management on a farm-individual basis.
\end{abstract}

Keywords: deworming; Eimeria; Fasciola hepatica; nematodes

\section{Introduction}

Even though they only represent a minor percentage (5.39\%) of kept cows in Germany, beef suckler cows are gaining importance in German cattle production [1]. "Pasture raised" products are considered healthier by consumers than conventional products [2]. Moreover, awareness of animal welfare and demand for high meat quality has grown over the last decade, especially in Europe [3]. Mother-bonded rearing of beef cattle calves is commonly seen as an animal-friendly system as the calves remain in a herd with their mothers up to the age of around nine months. The production system is economically efficient if performed pasture-based. This production system gives the animals the opportunity to express species-specific behaviour and it is known to have benefits for the animals' health and wellbeing [4]. There are several, also economically relevant health issues that are closely associated with this mother-bonded rearing system on pastures. One of these challenges, parasite pressure, seems to be becoming even more difficult to cope with due to increasing resistance against deworming medications worldwide [5]. Under those circumstances, a new focus on well-known management strategies could help to reduce parasite pressure as well as the amount of anthelmintics used on farms. When taking 
into account a study by Hallmann et al. [6] which claims a severe decline in flying insects, reducing anthelmintic use should also be considered for commercial farms as it would benefit dung-loving insects $[7,8]$. Different approaches to minimising the amount of anthelmintic medication are known. These include management strategies such as a number of approaches to rotational grazing [9] or a late turn out, reduction in stocking densities and pasture resting, among others [10]. Another approach are individual deworming strategies such as targeted treatment or targeted selective treatment, which are currently common in sheep (especially for Haemonchus contortus) as opposed to cattle [11] as detecting those individuals that need deworming is much simpler and cheaper. In order to provide and spread information about correct medication and the optimal timing for deworming, free online "decision tree" tools have been created in different languages [12]. Apart from the medication and environmental difficulties that come with the anthelmintic treatment, there are further problems related to parasite pressure: parasitic infections, even subclinical ones, can negatively affect the weight gain or growth of the animals, leading to significant economic losses. Besides decreased performance, parasitic infections can result in impaired health and welfare status of the animals, depending on the type and amount of parasites. Animals in their first grazing season are especially at risk due to several reasons: One of them is their lack of immunity as a non-sterile immunity towards parasitic diseases builds up after contact with the parasite, protecting adult animals to a certain degree [13].

Data on parasitic occurrence in suckler cows on a local database are rare. Previous studies reveal that Eimeria, gastrointestinal nematodes (GIN) and Fasciola hepatica are predominant findings in beef cattle within Northern and Central Europe $[14,15]$. The occurrence of parasites is strongly related to the environmental habitat of the host species, including climatic conditions. Therefore, parasitic load can differ regionally. As a logical consequence, information on the status quo in suckler cow herds is essential to develop suitable management recommendations. The aim of this study was to gain data on the parasitic status quo in beef suckler cows in representative regions in Germany. Based on these data, the second aim was to identify risk factors for parasitic occurrence and, if necessary, to develop recommendations to reduce parasitic occurrence in beef suckler cow herds.

\section{Materials and Methods}

\subsection{Farm Selection and Animals}

For the presented on-farm study, beef suckler cow herds (Aberdeen and German Angus) on five farms (Farms A-E) in four representative regions of Germany were monitored with regard to their parasitological status over a period of 17 months between May 2015 and September 2016. Herd size on the five farms varied between 48 and 411 adult animals, respectively. All animals were kept on pastures in the summer season (April to October) and housed in barns in the winter season (October to April). Farm E did not provide a barn for the animals, but appropriate weather protection. An overview of the farm characteristics is presented in Table 1.

Table 1. Characteristics of the farms.

\begin{tabular}{cccccc}
\hline Parameter & Farm A & Farm B & Farm C & Farm D & Farm E \\
\hline Region & $\begin{array}{c}\text { Central } \\
\text { Germany }\end{array}$ & $\begin{array}{c}\text { Southern } \\
\text { Germany }\end{array}$ & $\begin{array}{c}\text { Southern } \\
\text { Germany }\end{array}$ & $\begin{array}{c}\text { German Baltic } \\
\text { coastal region }\end{array}$ & $\begin{array}{c}\text { Central } \\
\text { Germany }\end{array}$ \\
\hline Absolute altitude $(\mathrm{m})$ & 111 & 450 & 456 & 65 & 400 \\
\hline Average temperature $\left({ }^{\circ} \mathrm{C}\right)^{1}$ & 11.5 & 12.3 & 12.3 & 11.7 & 45.2 \\
\hline Average rainfall $\left(1 / \mathrm{m}^{2} / \mathrm{month}\right)^{1}$ & 59.4 & 48.6 & 48.6 & 65.7 \\
\hline Production & organic & organic & organic & conventional conventional \\
\hline
\end{tabular}


Table 1. Cont.

\begin{tabular}{|c|c|c|c|c|c|}
\hline Parameter & Farm A & Farm B & Farm C & Farm D & Farm E \\
\hline Herd size (adult cows) & 182 & 48 & 71 & 411 & 77 \\
\hline Pasture size (hectare) & 96 & 27 & 20 & 250 & 93 \\
\hline Pasture category & wet & dry & dry & wet & wet \\
\hline Grazing interval & 2-12 weeks & no rotation & no rotation & 3-6 weeks & 3-6 weeks \\
\hline Housing in winter season & barn & barn & barn & barn & $\begin{array}{l}\text { weather } \\
\text { protection }\end{array}$ \\
\hline Number of sampled calves & 21 & 25 & 17 & 17 & 23 \\
\hline Number of sampled heifers & 25 & 12 & 13 & 30 & 17 \\
\hline Number of sampled cows & 126 & 53 & 64 & 115 & 118 \\
\hline Not classified & 5 & 0 & 1 & 20 & 6 \\
\hline Total number of sampled animals & 177 & 90 & 95 & 182 & 164 \\
\hline
\end{tabular}

${ }^{1}$ Data provided by German Meterological Service, average data during the sampling period.

Weather data were provided by the German Meteorological Service (Deutscher Wetterdienst). It was used to categorise the farms' pastures in $\operatorname{dry}(\mathrm{B}, \mathrm{C})$ or wet $(\mathrm{A}, \mathrm{D}, \mathrm{E})$ conditions, along with data about rivers, ponds or wetlands in the specific areas. Farms A (110 m above sea level) and E (400 m above sea level) were located in the central Germany. On Farm D (65 m above sea level), which was located close to the coast of the Baltic sea, the pastures were relatively wet as they were located close to rivers or in wetland areas. Farms B and C (both approximately $450 \mathrm{~m}$ above sea level) were located in the South of Germany and raised their animals under rather dry conditions. Farms A, B, C were certified organic farms. Farms D and E kept their cattle at extensive stocking densities of up to 0.8 large livestock units per hectare. Weaned calves on farms A, B, C and E were kept on special pastures that had not been used by adult cows in the previous year.

Farmers were asked about their pasture management and deworming strategies via a standardised questionnaire. If possible, the information on medication was taken directly from the stable register recording all treatments of the animals. Pasture management varied between farms. Farm A had several smaller pastures (short grazing time of about two weeks in the area depending on the vegetation/feed) and some large pastures with longer grazing intervals of up to 12 weeks. Farms B and $C$ used year round short grass meadows, while farms $D$ and $E$ divided their large pastures into smaller areas for a rotational grazing system. The rotation was performed depending on the vegetation and regrowth on the pastures, as on farm A. The time interval for the rotation varied between three and six weeks.

\subsection{Sample Collection}

On each of the five farms, the aim was to collect approximately 19 faecal samples at two-month intervals. However, due to practical limitations, this aim could not be realised on two farms (B, C), resulting in 708 samples from nine sampling dates (time of data collection 1-9) in total. Whenever possible, the randomly picked samples were taken rectally during management procedures when the animals were driven through races. If there was no need for the farmers to drive their animals through races, samples were collected freshly after observed defaecation. All samples were collected by a trained veterinarian, who also examined the animals for clinical signs of parasitosis. Calves (from birth to weaning), heifers (from weaning to birth of the first calf) and cows (all others) were considered for sampling.

All samples were collected using veterinary gloves, placed in urinary cups, and stored in a cooler at $7{ }^{\circ} \mathrm{C}$ until analysis at the parasitological laboratory of the Clinic for Swine, Small Ruminants and Forensic Medicine (University of Veterinary Medicine Hannover, Germany) within $24 \mathrm{~h}$. The analyses of the samples were performed using the Baermen-Wenzel Test for Dictyocaulus, flotation for GIN (Ostertagia ostertagi, Trichostrongylus axei, Cooperia oncophora) and Nematodirus spp., Cestodes and 
Eimeria, and combined flotation and sedimentation for Trematodes (genera Fasciola, Calicophorum, Dicrocoelium) [16]. Qualitative analyses were performed for Eimeria oocysts using a modified McMaster method [16]. The oocyst count per gramme faeces (OCG) was determined for cows, heifers and calves.

\subsection{Statistical Analysis}

Statistical analysis was conducted using SAS software for Windows (Version 9.4, SAS Institute Inc., Cary, NC, USA). Parasitological status was analysed on a qualitative level using a binary score. The same was done for each parasitological parameter tested.

Data were analysed on a descriptive basis, using the procedure PROC FREQ in SAS. Additionally, a logistic regression model with Firth's bias correction was performed for the parasitological status in general and for the selected parasitological parameter (Eimeria spp., GIN and Fasciola hepatica). The model included the age status of the animal (adult, heifer, and calf), the farm (A-E) and the month of sample collection (1-9) as well as the interaction between farm and time of sample collection as fixed factors. The goodness of fit of the model was tested using the Hosmer-Lemeshow Test $(p<0.05$ for each model). Odds ratios (OR) were calculated. Results were considered statistically significant if the related $p$-values were less than 0.05 .

\section{Results}

\subsection{General Parasitological Status}

On the five farms, 708 samples were taken and analysed over a period of 17 months. Samples were almost equally distributed between the areas the farms were located in $\left(n_{\mathrm{A}}=177, n_{\mathrm{B}}=90\right.$, $\left.n_{\mathrm{C}}=95, n_{\mathrm{D}}=182, n_{\mathrm{E}}=164\right)$ with an emphasis on the age class of adult cows $\left(n_{\text {calves }}=103, n_{\text {heifers }}=97\right.$, $n_{\text {cows }}=476$, not classified: 32$)$. From all samples, $291(41.10 \%)$ were positive for one or more diagnostic findings. Clinical signs of parasitosis, for instance emaciation or scrubby coat, were neither observed in calves nor heifers or adults during the farm visits. On analysing the parasitological status in general a significant effect of the age status of the animal was revealed $(p<0.001)$. Calculated OR indicated a higher risk of young animals being infected compared to adult animals (calf vs. adult: 2.5; 95\% confidence interval (CI): 1.4-4.2; heifer vs. adult: 2.0; 95\% CI: 1.1-3.5) (Table 2).

Table 2. Odds ratios (OR) and 95\% confidence intervals (CI) for the risk factor age status of the animal with regard to general parasitological status, Eimeria spp., gastrointestinal nematodes (GIN) and Fasciola hepatica.

\begin{tabular}{ccccc}
\hline & Age Status & OR & $\mathbf{9 5 \%}$ CI & $p$-Value \\
\hline \multirow{2}{*}{ General parasitological status } & calf & 2.5 & $1.4-4.2$ & \\
& heifer & 2.0 & $1.1-3.5$ & $<0.001$ \\
& adult & 1.0 & - & \\
\hline \multirow{2}{*}{ Eimeria spp. } & calf & 4.5 & $2.5-7.9$ & \\
& heifer & 3.0 & $1.7-5.6$ & $<0.0001$ \\
& adult & 1.0 & - & \\
& calf & 2.1 & $1.3-3.6$ & $<0.01$ \\
& heifer & 1.9 & $1.1-3.2$ & \\
& adult & 1.0 & - & $<0.001$ \\
\hline \multirow{2}{*}{ Fasciola hepatica } & calf & 0.2 & $0.1-0.5$ & \\
& heifer & 0.3 & $0.1-0.7$ & - \\
\hline
\end{tabular}

Furthermore, general analysis showed an effect of the farm $(p<0.0001)$ and of the time of sample collection $(p<0.01)$ as well as an effect of the interaction between both $(p<0.05)$. For all parasites, 
lowest overall parasitic prevalence was found in winter (Figure 1); however, this factor varied among herds (Table 3).

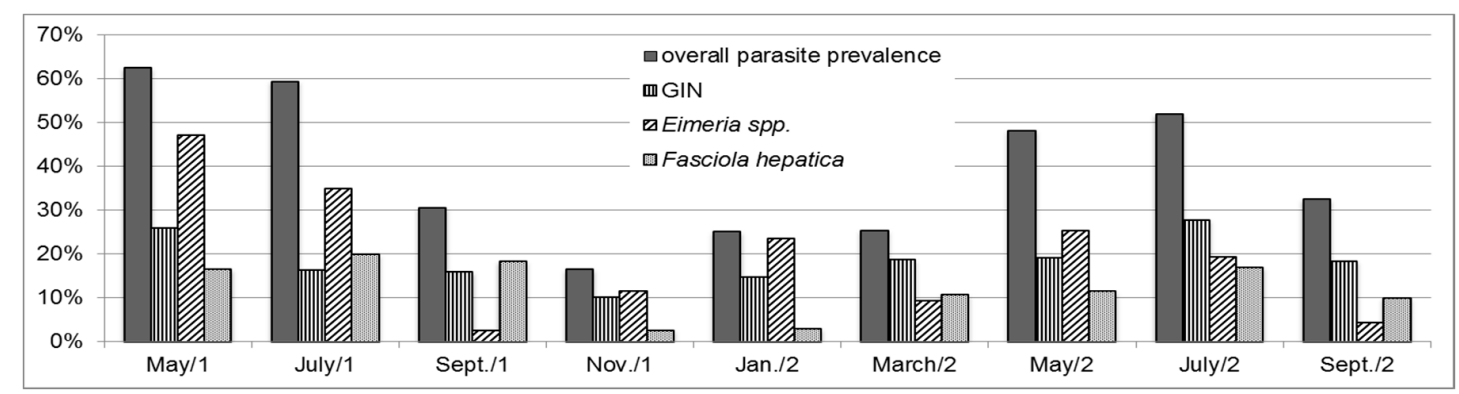

Figure 1. Occurrence of overall and most prevalent endoparasites in faecal samples of suckler calves, heifers and cows (in \% of all samples, $n=708$ ) in the course of 17 months from May in year one (May/1) to September in year two (September/2); GIN = gastrointestinal nematodes.

Table 3. Occurrence (in \%) of parasite species (in alphabetical order) in faecal samples $(n=708)$ of the five sampled herds (A-E).

\begin{tabular}{|c|c|c|c|c|c|}
\hline $\begin{array}{l}\text { Occurrence of Parasite } \\
\text { Species in \% }\end{array}$ & Farm $\mathrm{A}^{1}(n=177)$ & Farm B ${ }^{1}(n=90)$ & Farm $C^{1}(n=95)$ & Farm D $(n=182)$ & Farm E $(n=164)$ \\
\hline Capillaria spp. & 0.00 & 0.00 & 1.05 & 0.55 & 0.61 \\
\hline Dicrocoelium spp. & 0.00 & 0.00 & 2.11 & 0.55 & 0.61 \\
\hline Dictyocaulus viviparus & 0.00 & 2.22 & 2.11 & 0.55 & 17.68 \\
\hline Eimeria spp. & 22.60 & 18.89 & 16.84 & 23.08 & 17.07 \\
\hline Fasciola hepatica & 12.43 & 0.00 & 1.05 & 9.34 & 32.32 \\
\hline GIN & 21.02 & 20.00 & 15.79 & 19.78 & 15.85 \\
\hline Moniezia spp. & 3.95 & 4.44 & 2.11 & 1.65 & 2.44 \\
\hline Nematodirus spp. & 0.00 & 1.11 & 0.00 & 0.00 & 0.00 \\
\hline Calicophoron spp. & 1.02 & 0.00 & 0.00 & 0.55 & 4.88 \\
\hline Protostrongylus spp. & 0.00 & 0.00 & 0.00 & 0.00 & 0.00 \\
\hline Strongyloides spp. & 0.65 & 0.00 & 1.05 & 1.65 & 1.83 \\
\hline Trichuris spp. & 0.00 & 0.00 & 0.00 & 0.55 & 0.00 \\
\hline
\end{tabular}

\subsection{Eimeria spp.}

For all farms, the predominant parasite species found was Eimeria spp. with 143 positive samples (20.20\%), followed by GIN (132 positive samples, 18.67\%) and by Fasciola hepatica (93 positive samples, $13.14 \%$ ). Figure 1 shows the seasonal distribution of the overall occurrence as well as of the three predominant species. Due to the percentages of occurrence, detailed statistical analysis was performed for Eimeria spp., GIN and Fasciola hepatica.

Concerning Eimeria spp., statistical analysis of the oocyst occurrence revealed a significant effect of the age status of the animal $(p<0.0001)$. Calculated OR showed a higher risk of calves being infected compared to adult cows (calf vs. adult: 4.5; 95\% CI: 2.5-7.9), similar results also being found when comparing heifers to adult cows (heifer vs. adult: 3.0; 95\% CI: 1.7-5.6) (Table 2).

In detail, Eimeria spp. were found in almost half $(48.54 \%)$ of all samples taken from calves, in $35.05 \%$ of those from heifers and in $11.13 \%$ of adult samples. Statistical analysis also revealed a seasonal effect of the sample collection $(p<0.001)$. A peak in prevalence was found in May (Figure 1$)$. In contrast to the farms that kept their animals inside in winter, the highest Eimeria spp. prevalence on Farm E, where the animals were kept outside in wintertime, was found in May 2015 (42.11\% positive samples) on the summer pasture; and the lowest prevalence in March 2016 (0.00\%) on the winter pasture at freezing temperatures. With regard to the OCG, the highest counts found in this study were in calves' samples (Figure 2). However, no clinical signs for coccidiosis were found on the farm visits. 


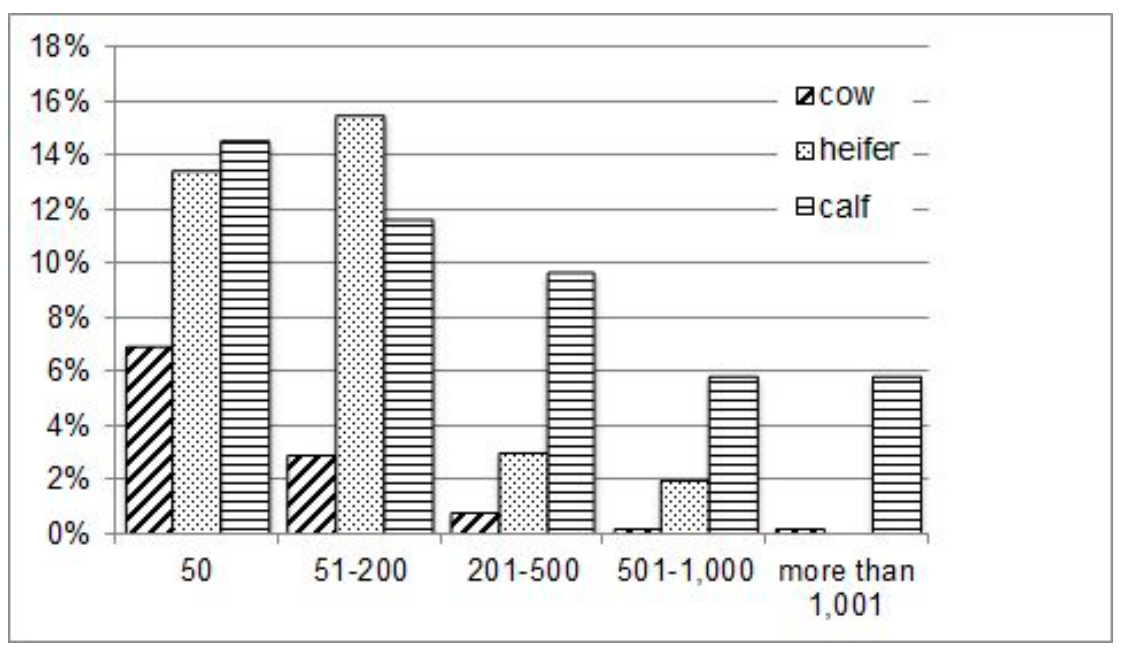

Figure 2. Distribution of samples with an oocyst count per gramme faeces (OCG) from 50 to more than 1001 oocysts in samples positive for Eimeria spp. (in \% of all samples, $n=143$ ) with regard to the age classes (cow, heifer, calf) in suckler cows.

\subsection{Gastrointestinal Nematodes (GIN)}

Analysing the distribution of GIN revealed a significant effect of the age status of the animal $(p<0.01)$, too, with calculated OR predicting a higher risk of calves being infected compared to adult animals (calf vs. adult: 2.1; 95\% CI: 1.3-3.6) and similar results for heifers compared to adult animals (heifer vs. adult: 1.9; 95\%CI: 1.1-3.2) (Table 2). However, compared to the parameter Eimeria, distribution was more balanced with $27.18 \%$ positive findings for the calves, $25.77 \%$ for the heifers and $16.00 \%$ for the adults.

\subsection{Fasciola Hepatica}

With regard to Fasciola hepatica, eggs were present on the three farms with rather wet pastures $(A, D, E)$, whereas they were only found in a small number of samples on one of the two farms with rather dry pastures (C). None were found on the other farm with dry pastures (B) (Table 3). Statistical analysis confirmed these results with significant effects on the farm $(p<0.0001)$. Analysis also revealed an effect of the age status of the animal $(p<0.001)$. Here, in contrast to the parasites mentioned above, calculated OR showed a higher risk for adult animals (calf vs. adult: $0.2 ; 95 \% \mathrm{CI}$ : $0.1-0.5$; heifer vs. adult: 0.3 ; 95\% CI: 0.1-0.7) (Table 2).

\subsection{Other Parasites}

Dictyocaulus were found in small quantities on farms B, C and D. None were found on farm A, while they were one of the major issues on farm E. Evidence for the presence of Moniezia was found on all farms with $1.65 \%$ (D) to $4.44 \%$ (B) of the animals being affected, respectively. Nematodirus, Trichuris, Capillaria, Strongyloides, Calicophoron and Dicrocoelium were found only infrequently and Protostrongylus was not found at all (Table 3).

\subsection{Deworming Strategies and Management}

Deworming strategies varied between the farms. The deworming strategy on each farm was not changed for the study in order to reflect a realistic situation of the parasitic pressure under given practical circumstances. Medication used on farms contained the following pharmaceutical ingredients: Deltanil, Ivermectine, Albendazole, Closantel plus Ivermectine, Moxidectine plus Triclabendazole, and Imidazothiazole. Animals were treated regularly at the beginning, middle and end of the summer season by the farmers using pour-on formulations. Additionally, calves on all farms were treated orally 
against Eimeria spp. on an individual basis if the farmer found clinical signs. No treatment against Eimeria was reported for heifers or adults.

On the organic farms, only young animals or adults with poor performance were treated in accordance with the regulations of organic farming. The only exception was the treatment against fasciolosis, with all animals on farms with positive test results for Fasciola being treated, even on organic farms. Farm C skipped the first deworming (summer 2015) and farm E cancelled the final deworming (summer 2016) within the sampling period.

\section{Discussion}

The monitoring of the occurrence of endoparasites in five German beef suckler cow herds showed a generally high occurrence of parasites, especially of Eimeria, GIN and Fasciola hepatica, with strong regional and seasonal influences. However, clinical signs for parasitic diseases were not found on the farm visits. Firstly, this can be related to subclinical infections. It is known that adult, healthy beef cattle can handle most parasitic infections well as long as the amount of parasites is relatively low, while calves, heifers or animals with immunosuppression are at higher risk of a clinical manifestation of parasitic diseases $[13,17]$. Nevertheless, subclinical infections can cause significant economic losses at all ages due to growth, performance and carcass quality reduction [18]. Secondly, animals, especially calves, in this study were immediately treated by the farmers when clinical signs were recognised. Considering egg shedding as an indicator for parasitic burden, it is important to note that egg shedding is intermittent and only a part of the infected animals can be detected via faecal samples. However, with the strict regulations for applying anthelmintic medication for organic farms and with the spread of resistant worm populations worldwide [10], the monitoring of parasites on farms is one, if not the only, option to optimise deworming and management strategies leading to a sustainable reduction in the parasitic burden. The higher findings in summer show that animals with access to pastures are especially at risk of contracting parasitic diseases [18].

Eimeria oocysts were found in samples of all age groups with higher OC in calves and heifers than adults. These results correspond with the common knowledge that Eimeria is a young animals' disease [19]. The constant reinfection with small amounts of eggs keeps immunity at a subclinical level in adult animals [20], showing no clinical signs of infection, but excreting oocysts. As Eimeria is transmitted via faecal-oral infection, higher occurrence in winter is a result of increased animal contact during the season in the barn. Therefore, adequate stable and also good pasture hygiene is one of the most important factors to keep infection rates low [19].

Like Eimeria infections, infections with GIN tend to be subclinical especially in adult animals, while weaned calves are at highest risk of developing clinical symptoms [21,22]. Immunity builds up slowly and is related to intensity and time of the infection of young animals [21]. This assumption corresponds with the results of our study as a significant influence of the animal's age status on the prevalence of GIN was found. Calves after weaning are particularly vulnerable to infections [22]. A strategy to improve the use of medication would be the deworming of heifers just before giving birth to their first calf, as cows tend to shed more eggs just after calving [23]. Strategies such as targeted (selective) treatment can also be beneficial: as only small groups or even individual animals receive treatment after prior analysis of faecal samples, ideally, a non-resistant parasite population, which can still be reduced by anthelmintics, is left on the pastures [24]. Moreover, appropriate pasture management can reduce GIN pressure: A late turn out of heifers can minimise the risk of severe infections as the overwintered larvae die in late spring [10]. In Western Europe, beef suckler cows and their calves are kept together on pasture until weaning which, besides welfare aspects, can have positive effects on parasitic pressure. The adult animals eat more grass, and with that parasite eggs, than the milk calves, reducing the infection-risk for the calves if the stocking density is not too high [17]. A simple recommendation to improve management for grazing animals in their first year to reduce GIN pressure is to put them on a "clean" pasture. In this context "clean" means the pasture not used by cattle in the previous year, but a hay meadow, lying idle or used by other grazing species apart from 
ruminants [18]. For instance, this can be realised by using parts of the area for winter feed production for young stock in spring, rotating annually.

It has to be stated that proper pasture management does not only have a positive effect on GIN occurrence, but also on all developmental stages of parasites in the outer environment. The standard pasture management procedures on the farms in this study were year-round pastures $(\mathrm{B}, \mathrm{D})$ or a rotation system on rather large pastures, where the animals stayed for some weeks or even months (A, C and E). Sometimes grazing time was shorter due to local conditions, but none of the participating farmers intended to use intensive rotational grazing systems on a daily rotating basis due to the work-load. However, intensive rotational grazing techniques are performed worldwide (for instance, "TechnoGrazing" [25]) and have become the focus of attention again lately because of concerns about growing anthelmintica resistance and the need for increased productivity per hectare compared to long rotation intervals or even year-round meadows.

The prevalence of Fasciola hepatica in this study was high on farms with wet pastures in central and northern parts of Germany. Even though the pastures of the southern farms were located in rather dry regions, Fasciola hepatica was found in low percentages on one of the two farms in that region. This demonstrates that even farms located in dry regions cannot renounce treatment before investigating the status of the herd by means of faecal sampling. The occurrence of Fasciola hepatica is related to wetland as a habitat of the intermediate host Galba truncatula [26]. Fencing out wet areas such as lakes or swamps within the pastures is not always successful because the snails move further from their habitat in wet conditions, e.g., rainy weather, and also use secondary habitats such as puddles or trampled areas around the water trough. None of the farmers in this study fenced out in wet areas. Rommel and Schnieder (1989) [27] stated that eggs of Fasciola hepatica can be excreted even some months after the death of the flukes due to medical treatment with fasciolizide because eggs can survive within the bile ducts. Apart from the fact that not all animals in this study received treatment, especially on the organic farms, this might be the reason for finding Fasciola hepatica eggs in winter. Theoretically, resistance could be another possible explanation. Reinfection in winter is unlikely in a continental climate, as intermediate hosts are not found below $6{ }^{\circ} \mathrm{C}$ [28].

In this study, other trematodes were only found very rarely (Calicophoron spp.) or not at all (Dicrocoelium dendriticum). Regarding Dictyocaulus viviparus, contrary to other studies [29,30], claiming a seroprevalence of about $41 \%$ in grazing cattle, the larvae thereof were rarely detected in our study. This parasite is known to affect animals of all age groups and is usually a group problem rather than an individual animal finding. Massive restrictions in animal health and welfare are possible due to the induced respiratory insufficiencies. The high prevalence of $17.68 \%$ on one farm (E) was very likely the result of skipping the last deworming in summer 2016 because prior to this prevalence had been as low as on the other farms.

To reduce the general occurrence of parasites, apart from the specific management procedures described above, there is still room for improvement. The manner in which deworming is practised on farms is essential. In this study, pour-on formulations were preferred as they seem easy to apply. However, in winter especially, the thick coat of the animals and dirt can inhibit the contact between medication and skin if the pour-on is not applied carefully and correctly. Pouring the medication on the coat instead of on the skin can lead to an insufficient level of active agents, probably resulting in the development of resistance. Overall, different approaches to reduce deworming medication might become interesting tools in future especially for the growing number of organic farms, but also for commercial ones as resistance is spreading worldwide. These could be management strategies such as intensive rotational grazing, as discussed above, but also innovative approaches such as the supplementation of fungal spores against parasites [31] or the use of Indian runner ducks to reduce mollusks as intermediate hosts [32]. The selection and breed of resistant or resilient animals might be another approach [33]. 


\section{Conclusions}

Based on the results of this study, it can be concluded that assessing parasitological status should become a routine procedure, especially on organic farms where prophylactic treatment is prohibited, and on commercial farms too. Such tests at herd, or better group level, would help to establish an improved parasite-control management on a farm-individual basis. This would include a combination of therapeutical deworming and improved grassland management.

Author Contributions: Conceptualization, K.G., R.W. and N.K.; Field Work: K.G. and T.H.; Methodology, K.G. and N.K.; Statistical Analysis, K.G. and J.S.; Validation, T.H, J.S., R.W. and N.K.; Formal Analysis, J.S. and N.K.; Writing-Original Draft Preparation, K.G.; Writing-Review and Editing, N.K.; Visualization, K.G. and N.K.; Supervision, N.K.; Project Administration, K.G. and N.K.; Funding Acquisition, R.W. and N.K.

Funding: This study was part of the project "Analysing and improving the relationship between grasslands, animal health and animal breeding in suckler cows: MuKuGreen". It was funded by the Federal Ministry of Food and Agriculture, Germany, based on a decision of the Bundestag within the Federal State Programme for Organic Farming and other Forms of Sustainable Farming (Bundesprogramm ökologischer Landbau und andere Formen der nachhaltigen Landwirtschaft (BÖLN)).

Acknowledgments: The authors are grateful for the farmers' support.

Conflicts of Interest: The authors declare no conflict of interest. The funders had no role in the design of the study; in the collection, analyses, or interpretation of data; in the writing of the manuscript, and in the decision to publish the results.

\section{References}

1. DE-Statis, Statistisches Bundesamt. Available online: https://www.destatis.de/DE/ZahlenFakten/ Wirtschaftsbereiche/LandForstwirtschaftFischerei/TiereundtierischeErzeugung/Tabellen/ BetriebeRinderBestand.html (accessed on 5 August 2018).

2. Conner, S.; Oppenheim, D. Demand for pasture-raised livestock products in Michigan: Results of consumer surveys and experimental auctions. J. Food Distr. Res. 2008, 39, 45-50.

3. Fernqvist, F.; Ekelund, L. Credence and the effect on consumer liking of food-A review. Food Qual. Prefer. 2014, 32, 340-353. [CrossRef]

4. Gemma, L.; Charlton, S.; Rutter, M. The behaviour of housed dairy cattle with and without pasture accessA review. Appl. Anim. Behav. Sci. 2017, 192, 2-9.

5. Demeler, J.; Van Zeveren, A.M.J.; Kleinschmidt, N.; Vercruysse, J.; Höglund, J.; Koopmann, R.; Cabaret, J.; Claerbout, E.; Areskog, M.; von Samson-Himmelstjerna, G. Monitoring the efficacy of ivermectin and albendazole against gastro intestinal nematodes of cattle in Northern Europe. Vet. Parasitol. 2009, 160, 109-115. [CrossRef] [PubMed]

6. Hallmann, C.A.; Sorg, M.; Jongejans, E.; Siepel, H.; Hofland, N.; Schwan, H.; Stenmans, W.; Müller, A.; Sumser, H.; Hörren, T.; et al. More than 75 percent decline over 27 years in total flying insect biomass in protected areas. PLoS ONE 2017, 12, e0185809. [CrossRef] [PubMed]

7. Strong, L.; Wall, R.; Woolford, A.; Djeddour, D. The effect of feacally excreted ivermectin and fenbendazol on the insect colonization of cattle dung following the oral administration of sustained-release boluses. Vet. Parasitol. 1995, 62, 253-266. [CrossRef]

8. Beynon, S.A.; Peck, M.; Mann, D.J.; Lewis, O.T. Consequences of alternative and conventional endoparasite control in cattle for dung-Associated invertebrates and ecosystem functioning. Agric. Ecosyst. Environ. 2012, 162, 36-44. [CrossRef]

9. Voison, A. Grass Productivity; Philosophical Library Inc.: New York, NY, USA, 1959.

10. Vercruysse, J.; Dorny, P. Integrated control of nematode infection in cattle. A reality? A need? A future? Int. J. Parasitol. 1999, 29, 165-175. [CrossRef]

11. Fahrenkrog, J.; Koopmann, R.; von Samson-Himmelsterna, G.; Demeler, J. Targeted Selective Treatment (TST) bei Rindern zur Reduzierung der Resistenzbildung bei Endoparasiten. In Landbauforschung Sonderheft; Johann Heinrich von Thünen-Institut: Braunschweig, Germany, 2011; Volume 346, pp. 71-76.

12. Ploeger, H.W.; Van Doorn, D.C.K.; Nijsse, E.R.; Eysker, M. Decision trees on the web-A parasite compendium. Trends Parasitol. 2008, 24, 203-204. [CrossRef] [PubMed] 
13. Shaw, D.J.; Vercruysse, J.; Claerebout, E.; Dorny, P. Gastrointestinal nematode infections of first-grazing season calves in Western Europe: General patterns and the effect of chemoprophylaxis. Vet. Parasitol. 1998, 75, 115-131. [CrossRef]

14. Kemper, N.; Henze, C. Effects of pasture's re-wetting on endoparasites in cattle in northern Germany. Vet. Parasitol. 2009, 161, 302-306. [CrossRef] [PubMed]

15. Tander, F. Untersuchungen zum Vorkommen und zur Epidemiologie von Endoparasitosen bei Kühen in verschiedenen Haltungssystemen. Ph.D. Thesis, Ludwig-Maximiliam-University, Munich, Germany, 2004.

16. Schmäschke, R. Die Koproskopische Diagnostik von Endoparasiten in der Veterinärmedizin; Schlütersche: Berlin, Germany, 2014.

17. Deinhofer, G. Weidemanagement: Möglichkeiten in der Parasitenregulation bei Rind und Kleinen Wiederkäuern. In Proceedings of the Parasitologische Fachtagung für Biologische Landwirtschaft, Raumberg-Gumpenstein, Austria, 22 March 2009; pp. 9-13.

18. Hawkins, J.A. Economic benefits of parasite control in cattle. Vet. Parasitol. 1993, 46, 159-173. [CrossRef]

19. Rommel, M. Protozoen. In Veterinärmedizinische Parasitologie, 4th ed.; Boch, J., Supperer, R., Eds.; Verlag Paul Parey: Berlin/Hamburg, Germany, 1992; pp. 109-174.

20. Heile, C. Orientierende Untersuchungen zur Parasitenkontrolle bei Mutterkuhherden auf unterschiedlichen Standorten in Brandenburg. Ph.D. Thesis, Free University, Berlin, Germany, 1999.

21. Bürger, H.-J. Helminthen. In Veterinärmedizinische Parasitologie, 4th ed.; Boch, J., Supperer, R., Eds.; Verlag Paul Parey: Berlin/Hamburg, Germany, 1992; pp. 174-322.

22. Armour, J. The epidemiology of helminth disease in farm animals. Vet. Parasitol. 1980, 6, 7-46. [CrossRef]

23. Connan, R.J. Effect of lactation on the immune response to gastro-intestinal nematodes. Vet. Rec. 1976, 99, 476-477. [CrossRef] [PubMed]

24. Schwörling, J. Erprobung des "Targeted Selective Treatment" mit Levamisol zur Endoparasitenbekämpfung bei Lämmern. Ph.D. Thesis, University of Veterinary Medicine, Hannover, Germany, 2016.

25. Precision Grazing. Available online: http://www.precisiongrazing.com/technograzingtm/ (accessed on 5 August 2018).

26. Knubben-Schweizer, G.; Scheuerle, M.; Pfister, K. Die bekämpfung des großen leberegels beim rind. Tierarztl Prax Großtiere 2011, 3, 179-185.

27. Rommel, M.; Schnieder, T. Neue Anthelminthika und neue Behandlungssysteme zur Behandlung von Weideparasitosen der Rinder. Angew. Parasitol. 1989, 30, 101-109. [PubMed]

28. Christensen, N.; Nansen, P.; Frandsen, F. The influence of temperature on the infectivity of Fasciola hepatica miracidia to Lymnea truncatula. J. Parasitol. 1976, 62, 698-701. [CrossRef] [PubMed]

29. Ploeger, H.W.; Borgsteede, F.H.M.; Sol, J.; Mirck, M.H.; Huyben, M.W.; Kooyman, F.N.J.; Eysker, M. Cross-sectional serological survey on gastrointestinal and loung nematode infections in first and second-year replacement stock in the Netherlands: Relation with management practise and use of anthelmintics. Vet. Parasitol. 2000, 36, 57-70. [CrossRef]

30. Schnieder, T.; Bellmer, A.; Tenter, A.M. Seroepidemiologigal study on Dictyocaulus viviparus infections of first grazing cattle in Northern Germany. Vet. Parasitol. 1993, 47, 289-300. [CrossRef]

31. Holst, C.R. Untersuchungen zum Einfluss nematophager Pilze auf das Nematoden-Infektionsrisiko bei Schafen und Ziegen. Ph.D. Thesis, University of Veterinary Medicine, Hannover, Germany, 2005.

32. Hull, J. Ducks and the control of liver fluke in sheep. Vet. Rec. 2017, 181, 270-271. [CrossRef] [PubMed]

33. Albers, G.A.A.; Gray, G.D. Breeding for worm resistance: A perspective. Int. J. Parasitol. 1987, 12, 559-566. [CrossRef]

(C) 2018 by the authors. Licensee MDPI, Basel, Switzerland. This article is an open access article distributed under the terms and conditions of the Creative Commons Attribution (CC BY) license (http:/ / creativecommons.org/licenses/by/4.0/). 